\title{
Development of Recommendations for the Construction of Transmission Paths for Generating Powerful Electromagnetic Radiation
}

\author{
Valentin Chimshir ${ }^{1}$, Tetiana Prokopenko ${ }^{2}$, Andrii Kononenko ${ }^{3}$, Leonid Gerganov ${ }^{4}$, Oleksandr Danylenko ${ }^{5}$ \\ Anzhela Haidarzhy ${ }^{6}$ \\ ${ }^{1}$ Director of the Institute, Danube Institute of National University of "Odessa Maritime Academy", Ukraine \\ scopus667@gmail.com \\ ${ }^{2}$ Department of Automation of Production Processes, Central Ukrainian National Technical University, Ukraine, \\ arabeska@ukr.net \\ ${ }^{3}$ Head of the scientific and organizational department Institute of Vocational Education, National Academy of Pedagogical Sciences of \\ Ukraine, Ukraine, \\ svpukononenko@gmail.com \\ ${ }^{4}$ Department of engineering disciplines, Danube Institute of National University of “Odessa Maritime Academy”, Ukraine \\ scopus667@gmail.com \\ ${ }^{5}$ Department the Navigation and Ship Handling, Danube Institute of National University of "Odessa Maritime Academy”, Ukraine \\ scopus667@gmail.com
}

\begin{abstract}
An overview of the three main directions of creation of means for generating powerful electromagnetic radiation with an ultra-short duration of the possible use of means that can generate powerful electromagnetic pulses of ultrashort duration is carried out. A variant of constructing transmission paths for creating means that can generate powerful electromagnetic pulses of ultrashort duration is proposed.
\end{abstract}

Key words: semiconductor, affection, probability, microprocessor technology, control system, space-time signal, mathematical model.

\section{INTRODUCTION}

At present, there are three main directions of development of means for generating powerful electromagnetic radiation with ultrashort duration [22-31].

1) based on video pulse generators;

2) based on Microwave relativistic generators of pulsed radio emission;

3) based on focusing electromagnetic radiation in Microwave transmitting phased antenna arrays.

These directions differ significantly both in the structure of the generated fields and in the mechanism of action on the target objects.

From the point of view of the field structure, these differences are primarily due to their spectral characteristics: video pulses do not have high-frequency filling and their spectrum can in principle occupy the frequency range $0 \ldots 1500 \mathrm{MHz}$ and more (in practice, it is limited by the band of emitting systems that "cut out" only certain areas from the total spectrum no more than $-25 \%$ of the central frequency of such a spectrum area); Microwave pulses are generated at a specific carrier frequency and their spectrum can occupy any place within the entire radio frequency range [3-5, 10-14]. The features of the spectrum of video pulses create serious problems for their directional channeling in space to the target, and for Microwave radiation such channeling is implemented by conventional antenna systems (horn, mirror, phased antenna arrays).

Within the framework of the second direction, it is fundamentally possible to create Microwave high-power pulses using oscillator lamps [15-18]: magnetrons, klystrons, vircators, gyrotrons, etc.

In the centimeter range, it is essential to use electron accelerators [18-21]. At a wavelength of $1 \mathrm{sm}$ for a pulse power of $500 \mathrm{MW}$ at a pulse duration $10 . . .12 \mathrm{~ns}$ known power amplifier based on a backward wave tube with a magnetic field $\mathrm{H}<2,4 \mathrm{kA} / \mathrm{m}$ [24]. At a wavelength of $10 \mathrm{sm}$ at the same power of $500 \mathrm{MW}$, the pulse duration was $16 \mathrm{~ns}$.

To obtain the required high pulse power, you can use several spaced radiation sources and direct them to one point in space [26-28, 31, 34].

Generation tools developed in the first two directions, although they have the above advantages, have two main disadvantages:

do not have properties of electromagnetic compatibility;

require the creation of special fundamentally new generator and antenna-feeder devices. 
Generation means developed within the first and second directions can provide the highest power per sample. However, they cannot be created on the existing element base.

Generation means created in the framework of the third direction have conditional secrecy, to a certain extent, the properties of electromagnetic compatibility and can be implemented using the existing industrialized generator and antenna-feeder devices. However, they can provide one sample (a radiation source in the form of a transmitting phased antenna array) more than an order of magnitude less power than the samples developed in the first and second directions. To increase the power and achieve the required values of the peak power flux density in the area of space where the moving suppressed or affected object is located, with restrictions on the peak power of an individual radiation source, it is possible to coherently summarize electromagnetic fields from a group of sources in its vicinity, i.e. to carry out focusing of electromagnetic radiation in a multi-position system of emitters. Consequently, the third direction of creation of means of generation with a short duration of acting pulses can be based on controlled focusing by electromagnetic radiation either in transmitting single planar phased antenna arrays, or in a multi-position system of planar phased antenna arrays and other typical radiators [18, 26-28, 31, 33, 34].

Since the use of generation means in most cases involves their placement on mobile mobile or mobile carriers, then rather stringent requirements are imposed on their weight and size characteristics and cost. Thus, the best known and proposed in $[27,28,36]$ is a space-phase-frequency method of focusing electromagnetic radiation, nevertheless, it still requires a rather complex hardware implementation, since to limit the scanning area under an aiming effect, it is required to use a space-time auxiliary degree of signal control in each channel of a phased antenna array, which leads to an increase in size and cost the latter, as well as some irrational energy losses due to irradiation of space outside the area where the suppressed or struck object is located.

It follows from the above that at the present stage, a more rational way to create means for generating powerful electromagnetic radiation is to use nanosecond Microwave impacting pulses formed on the basis of the third direction.

So, one of the promising directions for creating tools that can generate powerful electromagnetic pulses of ultrashort duration is the development of multifunctional radio equipment with transmitting phased antenna arrays that provide focusing of electromagnetic radiation to a given point in space. In this case, the parameters that control the formation of a given structure of the field and the achievement of the required power levels are not only the amplitude and phase distribution in the aperture of the phased antenna arrays, but also the frequency and time distribution. It should also be noted that in recent years, cylindrical phased antenna arrays, which have a number of advantages over flat ones, are of particular interest to developers for the implementation of means capable of generating powerful electromagnetic pulses. In this regard, a review of methods for focusing electromagnetic radiation with various possibilities for controlling current distributions in the aperture of a phased array antenna is of certain interest $[4,32$, 37].

Initially, the focusing problem arose when conducting short-range measurements of the radiation patterns of large-aperture antennas.

The spatial-phase methods of focusing electromagnetic radiation in the Fresnel zone used in this case have made it possible to achieve fairly good results $[1,35,36]$.

Modifications of traditional methods of controlled focusing of electromagnetic radiation using, on their basis, mutually coordinated spatial, amplitude, phase, frequency and time control of signal parameters along the aperture of emitters of a phased antenna array are the most universal.

At the same time, the main problematic issues are the need to develop fundamentally new pulse signal forming devices.

The purpose of the article is to develop recommendations for the construction of transmission paths for generating powerful electromagnetic radiation.

\section{MAin Material}

To assess the possibilities of constructing the shaping channels of the means for generating powerful electromagnetic radiation, it is also necessary to analyze various options for the technical implementation of the transmission channels of such means based on the equal-discrete single-stage and multi-stage $\mathrm{V}$-shaped frequency distributions over the aperture of a cylindrical phased antenna array: using digital and analog devices of transmission paths, systems synchronization and data transfer.

To fulfill the task of constructing transmission paths for the means of generating powerful electromagnetic radiation, it is necessary to present requirements for the parameters of a phased antenna array.

An antenna system design is proposed that allows generation in the frequency range from $10 \mathrm{GHz}$ to $12 \mathrm{GHz}$. So, as shown in [7, 37, 38], for a range of $\mathrm{R}=5 \mathrm{~km}$ in the means of generation, it is advisable to use a cylindrical phased antenna array with a maximum aperture size $\mathrm{L}=2,54 \mathrm{~m}$; lattice spacing along the guide $\mathrm{d}_{\mathrm{x}}=1.0 \lambda, \mathrm{d}_{\mathrm{y}}=0.8 \lambda$ where. For the number of emitters $\mathrm{M}_{\mathrm{x}}=88$ in the plane of the guide, the radius of the cylinder will be $1.25 \mathrm{~m}$, the number of emitters participating in the formation of the field $-\mathrm{N}=88 \times 20=1760$, antenna directivity $37 \mathrm{~dB}$. The refined value of the power supplied to the antenna when a single signal is emitted is $P_{\text {radiation }}=0,25 \mathrm{MW}$ or for one emitter $\mathrm{P}_{\text {radiation } 1}=142 \mathrm{~W}$. 
Compared with the focusing of electromagnetic radiation on the basis of nonlinear laws of space-phase-frequency and space-phase-frequency-time control of emitted signals, the use of equal-discrete $\mathrm{V}$-shaped frequency distributions over the aperture of a cylindrical phased antenna array when creating multifrequency space-time signals with a spatial method control allows to simplify the device for the formation of both single and bursts of periodic sequences of multifrequency spatio-temporal signals.

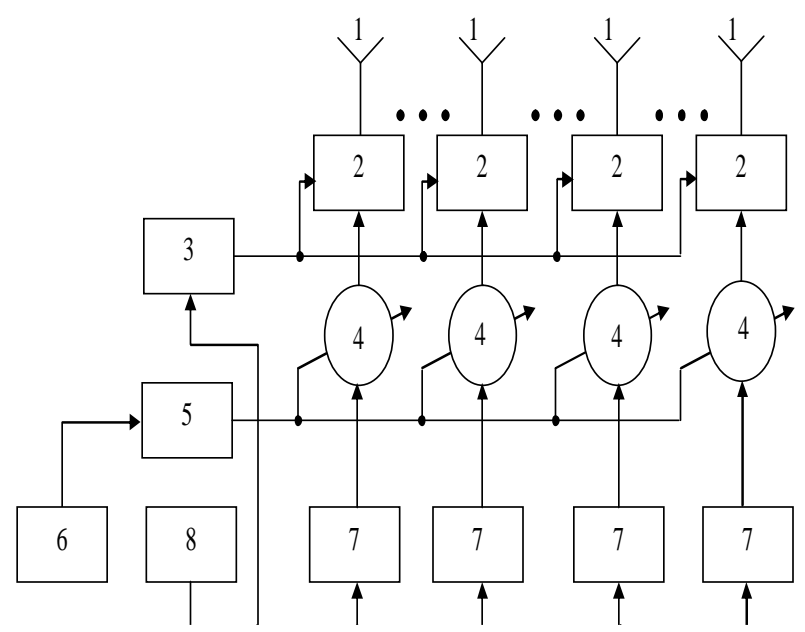

Figure 1: Block diagram of the transmitting channels of a cylindrical phased array antenna

The structural diagram of the proposed transmission path is shown in figure 1. Taking into account the fact that the number of elements of the phased antenna array, creating the required field in a given direction, is significantly less than the total number of elements of the phased antenna array, it can significantly simplify the design of the transmission path. A variant of constructing a transmitting phased antenna array with spatial-phase-frequency control of emitted signals is proposed, based on modern technical solutions based on solid-state semiconductor technology.

Figure 1 shows a block diagram of the transmitting channels of the claimed cylindrical phased array antenna, on which the designations are introduced: 1 - emitters; 2 - power amplifiers; 3 - pulse modulator; 4 - controlled phase shifters; 5 - phase shifter control system; 6 - special calculator; 7 - system for forming a coherent frequency grid; 8 - control unit.

The system for forming a coherent frequency grid is implemented using an indirect synthesis system based on a phase-locked loop (PLL). Such synthesizers make it possible to obtain a sinusoidal signal with a frequency of gigahertz and a resolution of less than one hundred hertz, synchronous to the reference frequency and phase stability no worse than that of the reference oscillator. In addition, PLL-based synthesizers provide the high spectral purity required for high-resolution radar equipment. Analog Devices manufactures a wide range of PLL chips and PLL synthesizers. PLL frequency synthesizers are represented by a family of 9 ADF4360-0 / $1 / 2 / 3 / 4 / 5 / 6 / 7 / 8$ microcircuits, implemented according to a single block diagram. The synthesizer circuit contains a built-in voltage controlled generator, a digital detector based on a phase comparator, an input divider with an integer division factor and a loop divider also with an integer division factor. Any microprocessor suitable for the respective tasks can be used as a control unit. In the phase shifters, which are controlled by the corresponding signals coming from the phase control unit (special calculator), the initial phases of the output signals are set depending on the selected angular direction of radiation.

With the help of a pulse modulator, for example the MI1 series, a pulsed mode of robots of nanosecond amplifiers is implemented in accordance with the selected mode. To achieve the specified output power, amplifiers such as MPKM-14500 / $\mathrm{R}$ from General Dynamics concern (up to $500 \mathrm{~W}$ at frequencies up to $14.5 \mathrm{GHz}$ ) can be used as amplifiers. The amplifier uses the addition of powers from 8-16 transistor subunits. In addition, they are equipped with advanced control, modulation, and dynamic range expansion subsystems.

\section{CONCLUSION}

Thus, the considered version of the technical implementation of the shaping channels of the means for generating powerful electromagnetic radiation based on the equal-discrete single-stage and multistage $\mathrm{V}$-shaped frequency distributions over the aperture of a cylindrical phased antenna array can be quite easily implemented on the basis of the use of digital devices for the formation of carrier frequencies using industrialized Microwave elements. transmission paths, synchronization and data transmission systems.

Based on the above, the technical implementation of the transmission channels of a cylindrical phased antenna array of means for generating powerful electromagnetic radiation is being further developed in comparison with those previously known based on the use of a harmonic generator.

\section{REFERENCES}

1 M. Iasechko. Plasma technologies for the protection of radio electronic means from exposure to high-power electromagnetic radiations with ultrashort pulse duration, Proceedings of the 1-st Annual Conference, Tallinn, Estonia, 2017, pp. 18-21. doi: 10.21303/2585-6847.2017.00480.

2 E. M. Bazelyan and U. P. Raizer. Lightning attraction mechanism and the problem of laser lightning control, Physics-Uspekhi, 43:7, Moscow, 2000, pp. 701-716.

3 V. L. Ginzburg and A. V. Gurevich. Nonlinear phenomena in a plasma located in an alternating electromagnetic field, SOV PHYS USPEKHI, 3(1), Moscow, 1960, pp.115-146. doi:10.1070/PU1960v003n01ABEH003261. 
4 O. G. Sytenko. Electromagnetic plasma fluctuations, KhGPU, Ukraine, Kharkiv, 1965, pp. 1-183.

5 S.A.Gutsev, A.A. Kudryavtsev, R.Yu. Zamchiy, V.I. Demidov, and V.I. Kolobov. Diagnostics and modeling of ashort (without positive column) glow discharge in helium with nonlocal plasma, Proc. 40th European Physical Society Conference on Plasma Physics, Finland, 2013, N 06.502.

6 M.M. Iasechko, and O.M. Sotnikov. Advanced technologies of radio electronic equipment (means) protection from powerful electromagnetic radiations with ultra short duration of pulses exposure, Published by Izdevnieciba Baltija Publishing, Collective monograph, Riga, 2018, pp.356-385.

7 I. Mac-Daniel. Collision processes in ionized gases, World, Moscow, 1967.

8 O.Skoblikov and V. Knyazyev. Properties of Conductive Shells Exposed to Electromagnetic Impulse of Lightning, International Conference on Lightning Protection (ICLP'2012), Vienna, Austrian, 2012, pp. 1-8.

9 A. Tajirov, I. Cwhanovskaya, and Z. Barsova, N. Iluoykha. Chemistry and technology of magnetite and barium-containing composite materials on its basis, European Science and Technology: materials of the II international research and practice conference, Wiesbaden Germany, 2012, pp. 80-87.

10 V.A. Chernikov, S.A. Dvinin, A.P. Ershov, I.B.Timofeev, and V.M. Shibkov. Experimental and Theoretical research of DC transversal gas discharge in a supersonic gas flow, The 3rd workshop on Magneto-Plasma-Aerodynamics in Aerospace Applications, Moscow, 2001, pp. 129-134.

11 B. M. Smyrnov. Low Ionized Gas Physics, The science, Moscow, 1985.

12 S.A. Dvinin, and A.A. Kuzovnikov. Plane ionization waves caused by diffusion in high frequency fields, $X V I I$ International Conference on Phenomena in Ionized Gases, Belgrade, 1989, pp. 818-819.

13 O. Sotnikov, M. Iasechko, V. Larin, O. Ochkurenko, and D.Maksiuta. The model of a medium for creation of electric hermetic screens of the radio electronic means, IJATCSE. 8(2), 2019, pp. 300-304. doi:10.30534/IJATCSE/2019/32822019.

14 M. Iasechko, O. Tymochko, Y. Shapran, I. Trofymenko, D. Maksiuta, and Y. Sytnyk. Loss definition of charged particles in the discharge gap of the opening of the box-screens during the formation of a highly conductive channel, IJATCSE. 8(1.3), 2019, pp. 1-9. doi: 10.30534/ijatcse/2019/0181.32019.

15 M. Iasechko, V. Larin, O. Ochkurenko, S. Salkutsan, L. Mikhailova, and O. Kozak. Formalized Model Descriptions Of Modified Solid-State Plasma-Like Materials To Protect Radio-Electronic Means From The Effects Of Electromagnetic Radiation, IJATCSE. 8(3), 2019, pp. 393-398. doi: 10.30534/ijatcse/2019/09832019.

16 M. Iasechko, V. Larin, O. Ochkurenko, A. Trystan, T.Voichenko, A. Trofymenko, and O. Sharabaiko. Determining the function of splitting the charged particles of the strongly ionized air environment in the openings of the case-screens of radioelectronic means, IJATCSE. 8(1.3), 2019, pp. 19-23. doi: 10.30534/ijatcse/2019/0481.32019.

17 M.M. Iasechko, and O.M. Sotnikov. Protecting of radio electronic facilities is from influence of powerful electromagnetic radiation, Published by Izdevnieciba Baltija Publishing, Collective monograph, Riga, 2019, pp.283-299.

18 A. Syrotenko, O. Sotnikov M. Iasechko, V. Larin, S.Iasechko O. Ochkurenko, and A. Volkov. Model of Combined Solid Plasma Material for the Protection of Radio-Electronic Means of Optical and Radio Radiation, IJATCSE, 8(4), 2019, pp. 1241 - 1247. doi:10.30534/ijatcse/2019/33842019.

19 V. Gurevich. Electromagnetic Terrorism: New Hazards. - Electrical Engineering and Electromechanics, N 4, 2005.

$20 \mathrm{Yu}$. P. Reiser. Breakdown and heating of gases under the action of laser beam, The successes of the physical sciences, 1965.

21 A.V. Bobylev, and V.A. Chuyanov. On the numerical solution of the Landau kinetic equation, Journal of Computational Mathematics and Mathematical Physics, T. 16. № 2, 1977, pp. $407-416$.

22 O. Turinskyi, M. Burdin, M. Iasechko, V. Larin, Y. Gnusov, D. Ikaev, V. Borysenko, and V. Manoylo. Protection of board radioelectronic equipment from the destructive powerful electromagnetic radiation with the use of natural technologies, IJETER, 7(11), 2019, pp. 542 - 548. doi: 10.30534/ijeter/2019/237112019.

23 M. Iasechko, V. Larin, D. Maksiuta, O. Ochkurenko, I. Krasnoshapka, Y.Samsonov, H. Lyashenko, A.Zinchenko, and R.Vozniak. Model description of the modified solid state plasma material for electromagnetic radiation protection, IJETER, 7(10), 2019, pp. 376 - 382. doi: 10.30534/ijeter/2019/027102019.

24 O. Turinskyi, M. Iasechko, V. Larin, D. Dulenko, V. Kravchenko, O. Golubenko, D.Sorokin, and O. Zolotukhin. Model and development of plasma technology for the protection ofradio-electronic means of laser emission, IJATCSE. 8(5), 2019, pp. 2429-2433. doi:10.30534/IJATCSE/2019/85852019.

25 M.Iasechko, Y. Gnusov, I. Manzhai, O. Uhrovetskyi, V.Manoylo, A. Iesipov,O. Zaitsev, M. Volk, and O. Vovk. Determination of requirements for the protection of radio-electronicequipment from the terroristic influence by electromagnetic radiation, IJETER, 7(12), 2019, pp. 772 - 777 . doi: 10.30534/ijeter/2019/077122019.

26. H. Khudov, R. Khudov, I. Khizhnyak, V. Loza, T. Kravets, S. Kibitkin Estimation of the Kullback-Leibler Divergence for Canny Edge Detector of Optoelectronic Images Segmentation, International Journal of Emerging Trends in Engineering Research, Vol. 8. № 7, 2020, pp. 3927-3934. DOI: doi:10.30534/ijeter/2020/162872020.

27. H. Khudov, S. Glukhov, O. Maistrenko, A. Fedorov, A. Andriienko, O. Koplik, The Method of ADS-B Receiver Systems Synchronization Using MLAT Technologies in the Course of Radar Control of Air 
Environment, International Journal of Emerging Trends in Engineering Research, Vol. 8. № 5, 2020, pp. 1946-1951. doi:10.30534/ijeter/2020/78852020.

28. I. Ruban, H. Khudov, O. Makoveychuk, I. Khizhnyak, V. Khudov, and V. Lishchenko The model and the method for forming a mosaic sustainable marker of augmented reality. 2020 IEEE 15th Inter. Conf. on Advanced Trends in Radioelectronics, Telecommunications and Engineering (TCSET), February 2020. pp. 402-406. doi:10.1109/TCSET49122.2020.235463.

29. H. Khudov, O. Makoveychuk, I. Khizhnyak, I. Yuzova , A. Irkha, and V. Khudov. The Mosaic Sustainable Marker Model for Augmented Reality Systems, International Journal of Advanced Trends in Computer Science and Engineering, Vol. 9. № 1, 2020, pp. 637-642. doi:10.30534/ijatcse/2020/89912020.

30 M. Iasechko, M. Kolmykov, V. Larin, S.Bazilo, H. Lyashenko, P. Kravchenko, N. Polianova and I. Sharapa. Criteria for performing breakthroughs in the holes of radio electronic means under the influence of electromagnetic radiation, ARPN Journal of Engineering and Applied Sciences, 15(12), 2020, pp. 1380 - 1384.

31 M. Iasechko, N. Sachaniuk-Kavets'ka, V.Kostrytsia, V.Nikitchenko and S. Iasechko. The results of simulation of the process of occurrence of damages to the semiconductor elements under the influence of multi-frequency signals of short duration, Journal of Critical Reviews, 7(12), 2020, pp. 109 - 112. doi:10.31838/jcr.07.13.18.

32 M. Iasechko, V. Larin, D. Maksiuta, S.Bazilo and I. Sharapa. The method of determining the probability of affection of the semiconductor elements under the influence of the multifrequency space-time signals, Journal of Critical Reviews, 7(9), 2020, pp. 569 - 571. doi: 10.31838/jcr.07.09.113.

33 O. Turinskyi1, M. Iasechko, V. Larin, T. Prokopenko, O. Kolmohorov, O. Salash, V. Tarshyn and Yu. Dziubenko. Determination of requirements for the protection of radio-electronicequipment from the terroristic influence by electromagnetic radiation, IJETER, 8(4), 2020, pp. $1333 \quad-\quad 1334$ doi: 10.30534/ijeter/2020/64842020.

34 T. Selivyorstova, A. Mikhalyov. Mathematical model of the two-phase zone supply of solidified metal castings under the influence of adjustable gas pressure. 2019.pp.25-28. doi:10.1109/ACITT.2019.8779914.

35 T. Selivyorstova, A. Mikhalyov. Analysis of Prediction Mathematical Models of Shrinkage Defects in Castings. 2018. pp.1-5. doi: 10.1109/SAIC.2018.8516811.

$36 \mathrm{Yu}$. Dotsenko, V. Selivorstov, T. Selivorstova, N. Dotsenko. Influence of heterogeneous crystallization conditions of aluminum alloy on its plastic properties. Naukovyi Visnyk Natsionalnoho Hirnychoho Universytetu. 2015. pp. 46-50.

37 I. Smyrnova, V. Horbenko, A. Lutsyshyn, V.Kaminskyi, Z. Sasiuk, T. Selivyorstova, I. Ienina. The Method of Determining the Probability of Affection of the Semiconductor Elements Under the Influence of the
Multifrequency Space-Time Signals, IJETER, 8(5), 2020, pp. $1776-1779$. doi: 10.30534/ijeter/2020/46852020.

38 I. Smyrnova, T.Selivyorstova, S. Liulchak, I.Sezonova, R.Yuriy, V.Liashenko. The results of simulation of the process of occurrence of damages to the semiconductor elements of radio-electronic equipment under the influence of multi-frequency signals of short duration, IJATCSE. 9(3), 2020, pp. 3053-3056. doi: 10.30534/ijatcse/2020/86932020. 